\title{
Nanofluid properties for forced convection heat transfer :a review
}

\author{
Mohsen Darabi ${ }^{1 *}$, Reza Naeimi ${ }^{2}$, Hamid Mohammadiun ${ }^{3}$,Saeed Mortazavi ${ }^{4}$ \\ ${ }^{I}$ Young Researchers and Elite Club, shahrood Branch, Islamic Azad University, shahrood, Iran \\ 2 process expert of Abadan oil refinery \\ ${ }^{3}$ Assistant Professor, Department of Mechanical Engineering, Shahrood Branch, Islamic Azad University, Shahrood, Iran \\ ${ }^{4}$ Assistant Professor, Department of chemical Engineering, Shahrood Branch, Islamic Azad University, Shahrood, Iran \\ *Corresponding author E-mail: mohsendarabi313@yahoo.com
}

Copyright $\odot 2015$ Mohsen Darabi et al. This is an open access article distributed under the Creative Commons Attribution License, which permits unrestricted use, distribution, and reproduction in any medium, provided the original work is properly cited.

\begin{abstract}
The thermal conductivity of nanofluids depends on various parameters, such as concentration, temperature, particle size, $\mathrm{pH}$, shape, material, and possibly on the manufacturing process of the nanoparticles. Data on the viscosity of nanofluids, available in the literature, are very limited. Theoretical models for the determination of the thermal conductivity and viscosity of nanofluids have been pursued. Experiments with nanofluids indicate that they higher heat transfer coefficients than the base fluid. No significant increase in a pressure drop is reported with nanofluids, compared with values with the base fluid. However, the stability of nanofluids with regard to settlement/agglomeration, especially at higher concentrations, is still a problem for practical applications.
\end{abstract}

Keywords: Nanofluids; Heat Transfer; Viscosity; Thermal Conductivity.

\section{Introduction}

Fluids containing small quantities of particles with magnitudes lower than $100 \mathrm{~nm}$ dispersed in a continuous medium, such as water, ethylene glycol, and engine oil, are termed 'nanofluids'. Rao [29]; the thermo-physical properties of nanofluids are higher than those of the base liquids. Eastman [10]; Lee [10], [19]; and all observed higher values of nanofluid thermal conductivity compared with the base liquid. The properties of aluminum oxide and copper oxide nanofluids based on water and ethylene glycol have been investigated widely because of their potential as heat transfer fluids in automotive and electronic cooling applications Maïga [21]; The classical analysis of Maxwell [31]; for twophase solid-liquid mixtures is the basis for the determination of the effective thermal conductivity of nanofluids. The model's predictions are satisfactorily for spherical-shaped particles at low-volume concentrations at ambient temperatures. The thermal conductivity of micron-sized solid suspensions is estimated using the Maxwell [31]; model. However, the model fails to predict the thermal conductivity of nanofluids.

\section{Thermal conductivity: theoretical models}

The model of Hamilton and Crosser [11]; is used widely for comparison of experimental data obtained by different investigators. The model is effective so long as the thermal conductivity of the particles is 100 times greater than the conductivity of the continuous phase. The influence of particle size and temperature is not considered in the model. The thermal conductivity predicted by the model is lower compared with experimental values. Modified Maxwell's model to predict the effective thermal conductivity of nanofluids. They assumed that the base fluid molecules close to the surface of the nanoparticles build a solid-like layered structure that has higher thermal conductivity than that of the base fluid. They combined the thermal conductivities of the solid particles and the nano-layer to arrive at an equivalent thermal conductivity of the nanofluid. Koo [17]; proposed a model to determine the effective thermal conductivity of a nanofluid as the sum of Maxwell's model and a term related to Brownian motion. This takes into account the effect of particle size, volume concentration, temperature, and properties of base fluid, as well as the nanoparticles subjected to 
Brownian motion. The combined Maxwell-Garnett conduction and convection, caused by the Brownian motion of the suspended particles, is the basis for thermal conductivity enhancement, According to Jang and Choi [16]; there are four modes that contribute to the energy transfer responsible for the enhancement of the thermal conductivity of nanofluids. The first mode is a collision between the base fluid molecules; the second is thermal diffusion in nanoparticles; the third is the collision of nanoparticles with each other due to Brownian motion; and the fourth is the collision between base fluid molecules and nanoparticles by thermally induced fluctuations. Hwang, K.[15];measured the thermal conductivities of A12O3, copper oxide, and zinc oxide nanofluids with nanoparticles dispersed in ethylene glycol (EG) and water in the ratio of 60:40 by mass. They conducted experiments in the temperature range of 298 to $363 \mathrm{~K}$ up to $10 \%$ volume concentration and developed a correlation for the estimation of nanofluid thermal conductivity similar to that of Koo [17]. It can be observed that different models have been developed to determine the thermal conductivity of nanofluids with the consideration of Brownian motion or with the concept of an interface between the particle and the liquid. Certain models include a parameter such as the mean free path of water, which is used in the process of obtaining dimensionless terms. Thus, theoretical determination of nanofluid thermal conductivity is semi empirical and material dependent.

\section{Thermal conductivity: experimental observation}

It can be observed that the theoretical models developed used certain empiricism in their equations. Hence, the determination of thermal conductivity based on experimentation has continued since the work of Lee et al [19]; using the concept of heat conduction under steady or transient methods. The experiments by Pak and Cho [28]; may be considered as pioneering work in estimating the properties of $\mathrm{Al} 2 \mathrm{O} 3$ nanofluid for the determination of heat transfer coefficients in the turbulent range. Lee et al [19]; conducted experiments for the determination of thermal conductivity in water and EG using $\mathrm{Al} 2 \mathrm{O} 3$ and $\mathrm{CuO}$ nanoparticles of 38 and $24 \mathrm{~nm}$, respectively. The experimental data with $\mathrm{Al} 2 \mathrm{O} 3 /$ water and $\mathrm{Al} 2 \mathrm{O} 3 / \mathrm{EG}$ are in reasonable agreement, whereas those from $\mathrm{CuO} / \mathrm{water}$ and $\mathrm{CuO} / \mathrm{EG}$ nanofluids showed higher values when compared with the Hamilton-Crosser model [11]. They reasoned that they obtained lower values of thermal conductivity with $\mathrm{Al} 2 \mathrm{O} 3 /$ water due to the larger particle size of $38 \mathrm{~nm}$ that they used, when compared with the values of Masuda [22]; who used 13-nm-sized particles. However, the deviation of the experimental values of $\mathrm{CuO}$ nanofluids with Hamilton and Crosser could not be explained [11]. Das [7]; observed the thermal conductivity of $\mathrm{CuO} /$ water nanofluid to rise from $2 \%$ to $10.8 \%$ at $1 \%$ and from $9.4 \%$ to $24.3 \%$ at $4.0 \%$ volume concentration when measured at temperatures between 21 and $55 \mathrm{oC}$. They reasoned that the Hamilton-Crosser equation could not predict the temperature dependence of the nanofluid [11]. Consequently, values evaluated with the equation are lower than those obtained from experiment are. Chon [5], [6]; proposed a semi empirical correlation for the determination of the thermal conductivity of an Al2O3 nanofluid considering Brownian motion. Mintsa [24]; conducted experiments to determine the thermal conductivity of aluminium oxide and copper oxide nanofluids in the temperature range of 20-50 $\mathrm{oC}$ and up to $18 \%$ volume concentration. All these experiments have predicted increasing values of thermal conductivity with concentration and temperature, and the values varied depending on the material. No significant variation in thermal conductivity can be observed between aluminum and copper oxide nanofluids. The thermal conductivity decreased with an increase in particle size at different volume concentrations. The investigators did not consider the influence of particle size in the development of their regression equations.

\section{Viscosity of nanofluids: theoretical models}

The viscosity of nanofluids has been investigated less than the thermal conductivity. Studies on the rheological properties of liquid suspensions commenced with Einstein's classical analysis. The Einstein equation can predict the effective viscosity of liquids in the low-volume fraction having spherical suspended particles. Brinkman [4]; extended the applicability to $4.0 \%$ particle volume concentration [4]. With increasing particle volume concentration, the neighboring particles affect the nature of flow around a particle. Batchelor [2]; studied the effect of these hydrodynamic interactions or the Brownian motion on the viscosity of suspensions and developed a relationship that is valid for particle volume concentrations up to $10 \%$ [2].

\section{Viscosity of nanofluids: experimental observation}

The viscosity of nanofluids has been determined experimentally by many researchers. Pak and Cho [28]; observed Newtonian behavior with $\mathrm{Al} 2 \mathrm{O} 3$ and $\mathrm{TiO} 2$ nanofluids at particle volume concentrations of less than $3 \%$ and $10 \%$ and for average diameters of 13 and $27 \mathrm{~nm}$, respectively. They observed that the viscosity decreased with temperature, although the viscosity of the nanofluid is much higher than that of the base fluid. Batchelor's model failed to predict the viscosity of the nanofluids, although the volume fraction of the particles is within the range of applicability. Nguyen [26], [27]; conducted experiments under ambient conditions, using different concentrations and particle sizes, to determine the viscosity of $\mathrm{Al} 2 \mathrm{O} 3$ and $\mathrm{CuO}$ nanofluids in water. Experiments revealed that the viscosity of $\mathrm{Al} 2 \mathrm{O} 3$ with particle sizes of 36 and $47 \mathrm{~nm}$ and that of $\mathrm{CuO}$ with particle sizes of $29 \mathrm{~nm}$ predicted similar values for volume 
concentrations of less than $4 \%$. Hence, the viscosity is independent of the properties of the material. Das et al [7]; developed a regression equation for the viscosity ratio as a function of concentration and particle diameter. Lee, Hwang [18]; conducted experiments with an $\mathrm{Al} 2 \mathrm{O} 3$ nanofluid in the volume concentration of less than $0.3 \%$ with 30 -nm-sized particles in the temperature range of 21 to $39^{\circ} \mathrm{C}$. The values of viscosity determined were always higher than those of the base liquid. The nanofluid viscosity increases with volume concentration and decreases with temperature. The influence of material on viscosity is insignificant for volume concentrations of nanofluid up to $4.0 \%$. The relative increase in viscosity can offset the advantage of enhanced thermal conductivity. Hence, the viscosity to thermal conductivity enhancement ratio can be an influential parameter on heat transfer enhancement.

\section{Properties evaluation}

Regression Model of Thermal Conductivity

The thermal conductivity data of metal and metal oxide nanofluids available in the literature are used in the development of regression equations. Pak and Cho [28]; Lee [19]; Murshed [25]; Das et al [7]; Chon [5], [6]; Mintsa [24]; and Beck [3], Avsec [1], Duangthongsuk [8], [9]; Sundar, Naik, Sharma, Singh, and Siva Reddy (2011), and Hong, Kim [14]; have all conducted experiments for the determination of thermal conductivity of nanofluids. Thermal conductivity depends primarily on the choice of material, concentration, temperature, and particle size. The influence of material on nanofluid thermal conductivity data is affected through the thermal diffusivity ratio of particles to water $(\alpha \mathrm{p} / \alpha \mathrm{w})$.

The correlation equation is validated with the data shown in the legend of Figure 1 with a maximum deviation of less than $11 \%$ for a few points. The particle sizes and the materials employed by the various investigators in the development of thermal conductivity of Eq. (1) are given in Table 1.

Regression Model of Viscosity

The experimental viscosity data of Nguyen et al. [16], Hwang and Choi [15]; Heris [13]; Nguyen [26], [27]; Lee [18]; Pak, and Cho [28]; He, Jin [12]; Duangthongsuk [8], [9]; and Lee, Park [20]; for volume concentrations of less than 4\%, comprising 233 data points. The data could be correlated with an average deviation of $3.18 \%$, a standard deviation of $3.8 \%$, and a maximum deviation of $13 \%$. The experimental data of viscosity for different nanofluids and variation of particle diameter are shown in Table 2.

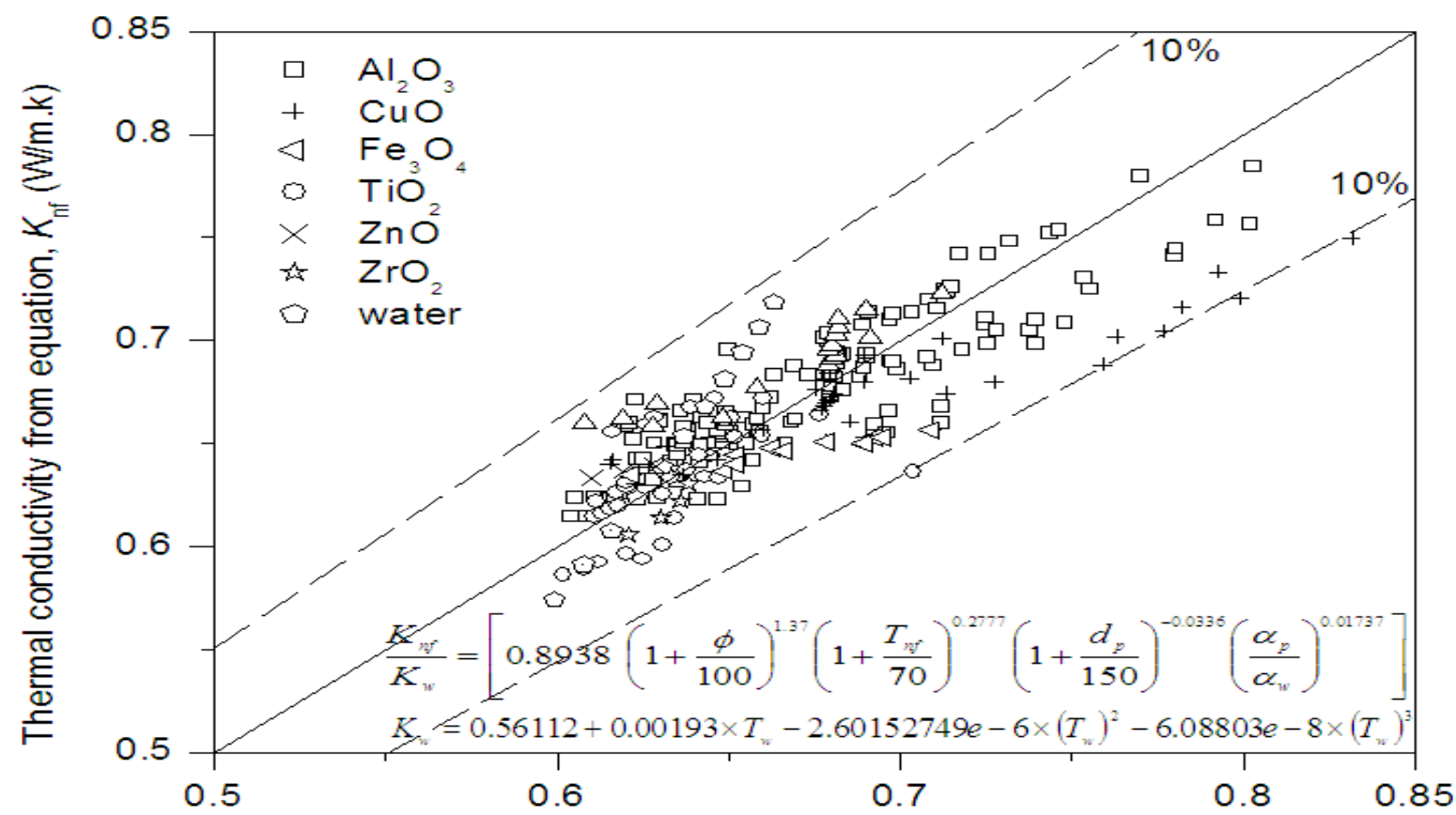

Thermal conductivity from experiment, $K_{n f}(\mathrm{~W} / \mathrm{m} . \mathrm{k})$

Fig. 1: Validation of Experimental Data with Eq. (1). 


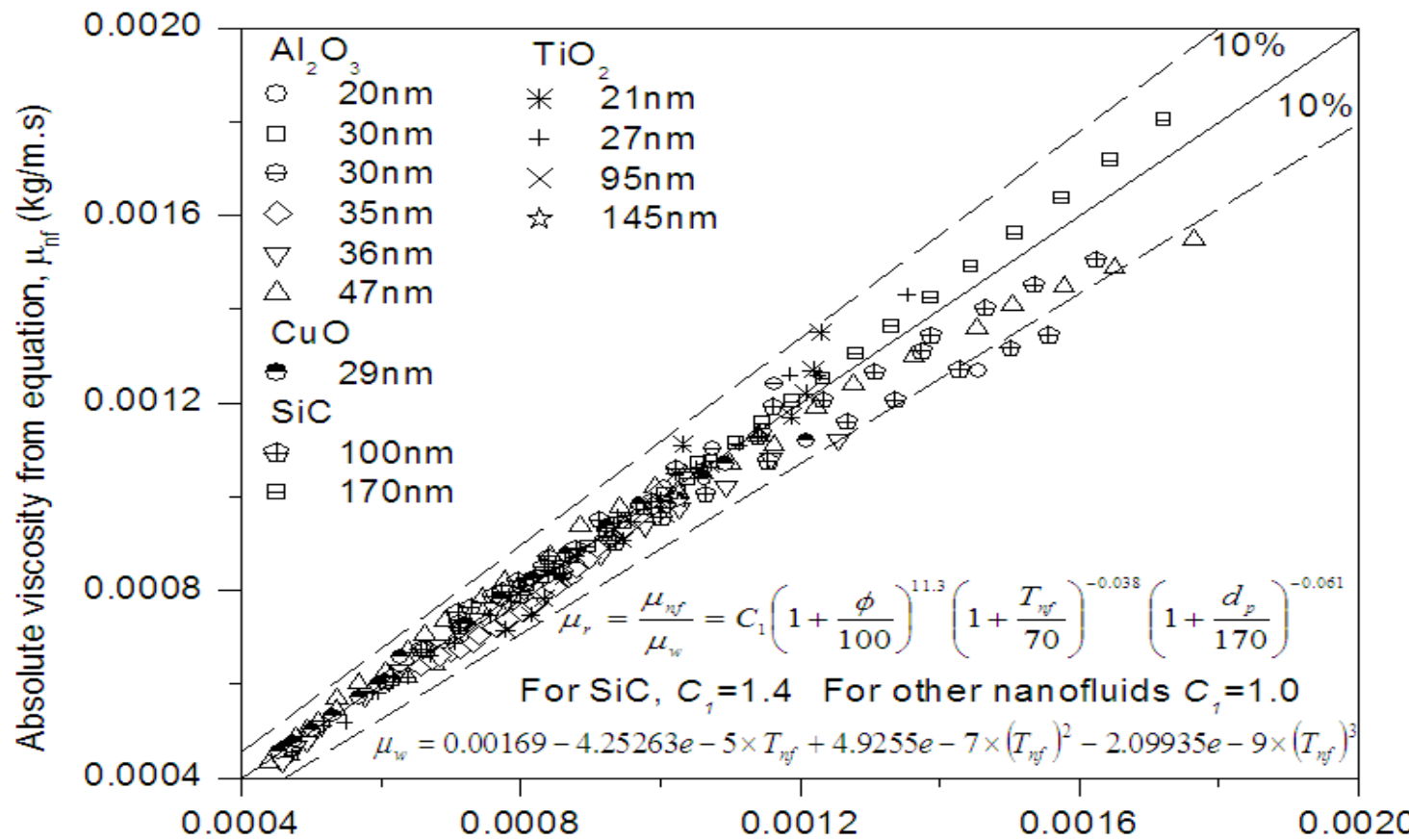

Absolute viscosity from experiment, $\mu_{n f}(\mathrm{~kg} / \mathrm{m} . \mathrm{s})$

Fig. 2: Validation of Data with the Eq. (2).

\section{Results and discussion}

Nanofluid properties, such as thermal conductivity and viscosity, are essential for the evaluation of heat transfer coefficients under different operating conditions. The opposing nature of the thermal conductivity rise and viscosity decrease with temperature, and the dependence of nanofluid thermal conductivity on material properties, alters the range of applicability of nanofluids for heat transfer applications. The estimations of viscosity and thermal conductivity values for metal- and oxide-based nanofluids, for concentrations of less than $4.0 \%$, are evaluated with the regression equations developed. Prasher et al, [23]; developed a condition for heat transfer enhancement based on an order of magnitude analysis. They observed that the ratio of enhancement in nanofluid viscosity to thermal conductivity should be lower than 4.0 in order for the nanofluid to show heat transfer enhancement. However, they did not relate the conditions to temperature and particle size. Pak and Cho [28]; and Duangthongsuk [8], [9]; reported a decrease in heat transfer coefficient with an increase in the concentration of the nanofluid. The regression equations developed for heat transfer could not explain the observations made by these investigators.

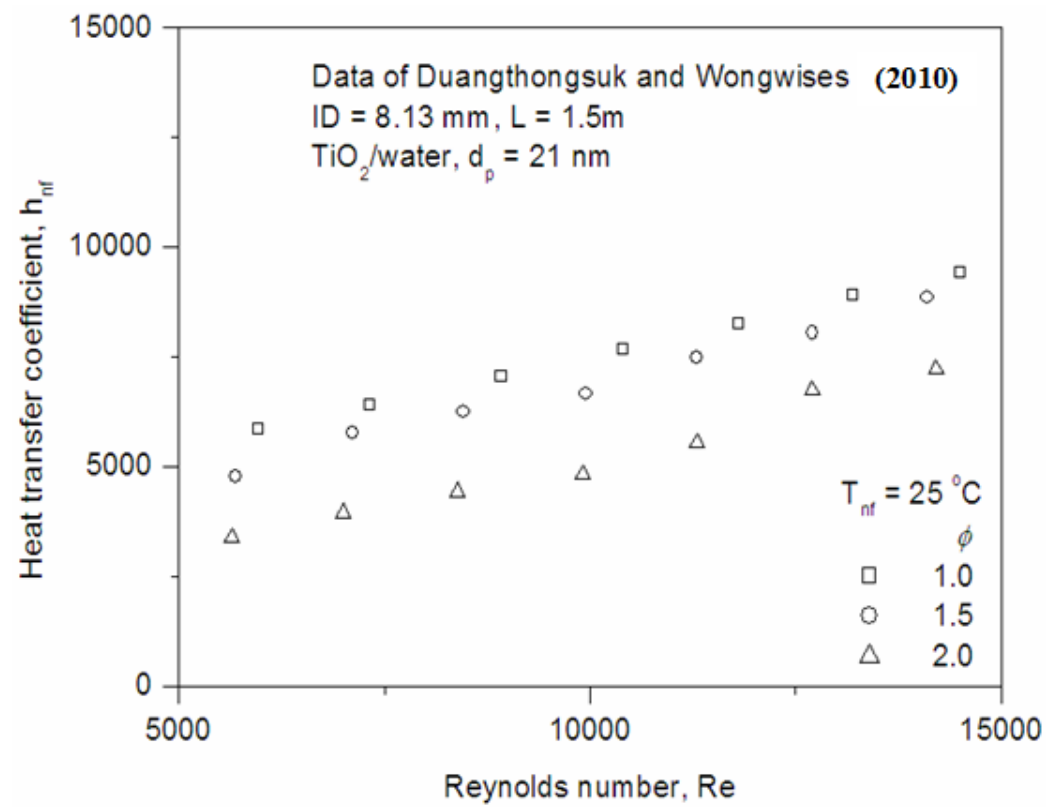

Fig. 3: Heat Transfer Data for Tio2 Nanofluids. 
The heat-transfer data of Duangthongsuk [8], [9]; are shown in Figure 3 for a TiO2 nanofluid undertaken at a temperature of $25 \mathrm{oC}$. The authors reported a decrease in a heat transfer coefficient with increasing concentration. To explain the decrease in heat transfer coefficient, Figure 4 presents the enhancement ratio and nanofluid temperature for 21-nm-sized particles, used by them using Eqs. (1) and (2). According to Prasher et al [23]; heat transfer enhancements are possible if the viscosity to a thermal conductivity enhancement ratio is lower than 4.0, which is shown as the thick horizontal line in Figure 4. As the experiments are undertaken at $25 \mathrm{oC}$, at all flow rates, the enhancement ratio is less than 4.0 for $1.0 \%$ concentration and greater for $2.0 \%$. The heat-transfer coefficient decreased because the enhancement in viscosity is higher than that of thermal conductivity of the nanofluid, when the concentration is increased from $1.0 \%$ to $2.0 \%$, as observed by the investigators.

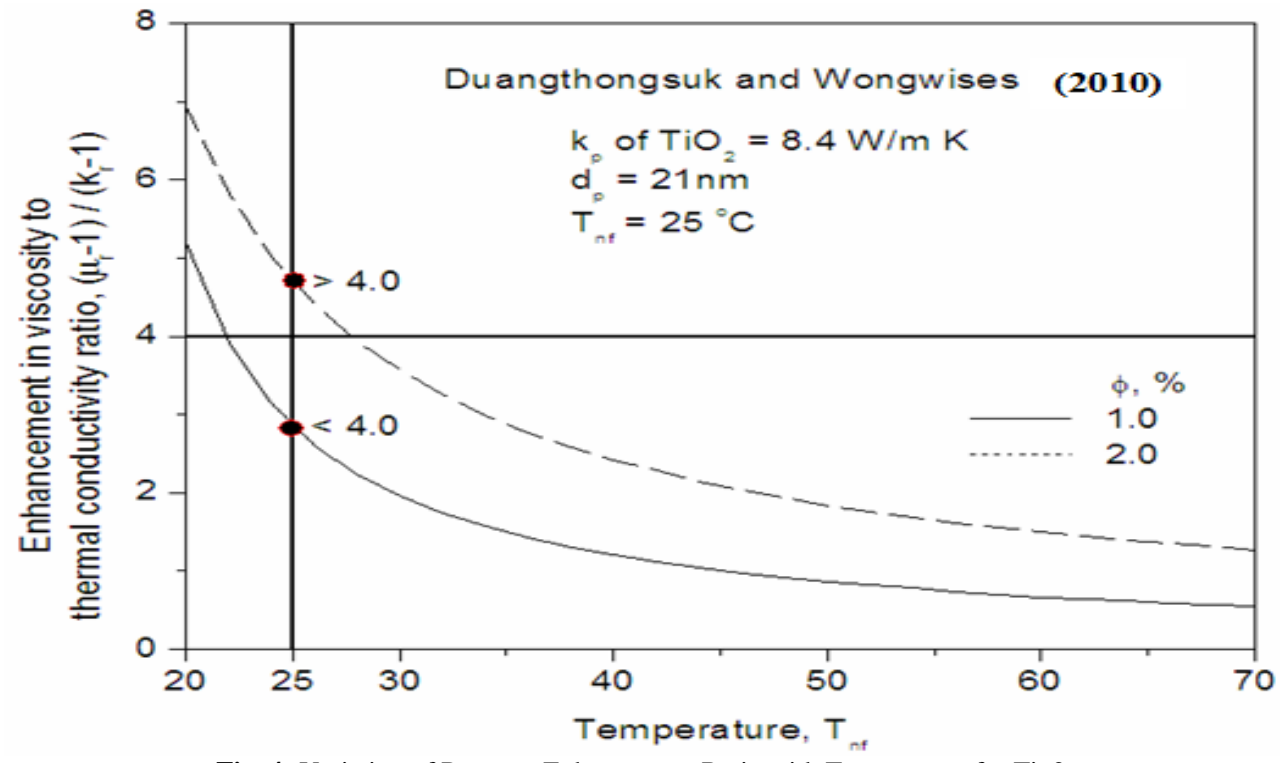

Fig. 4: Variation of Property Enhancement Ratio with Temperature for Tio2.

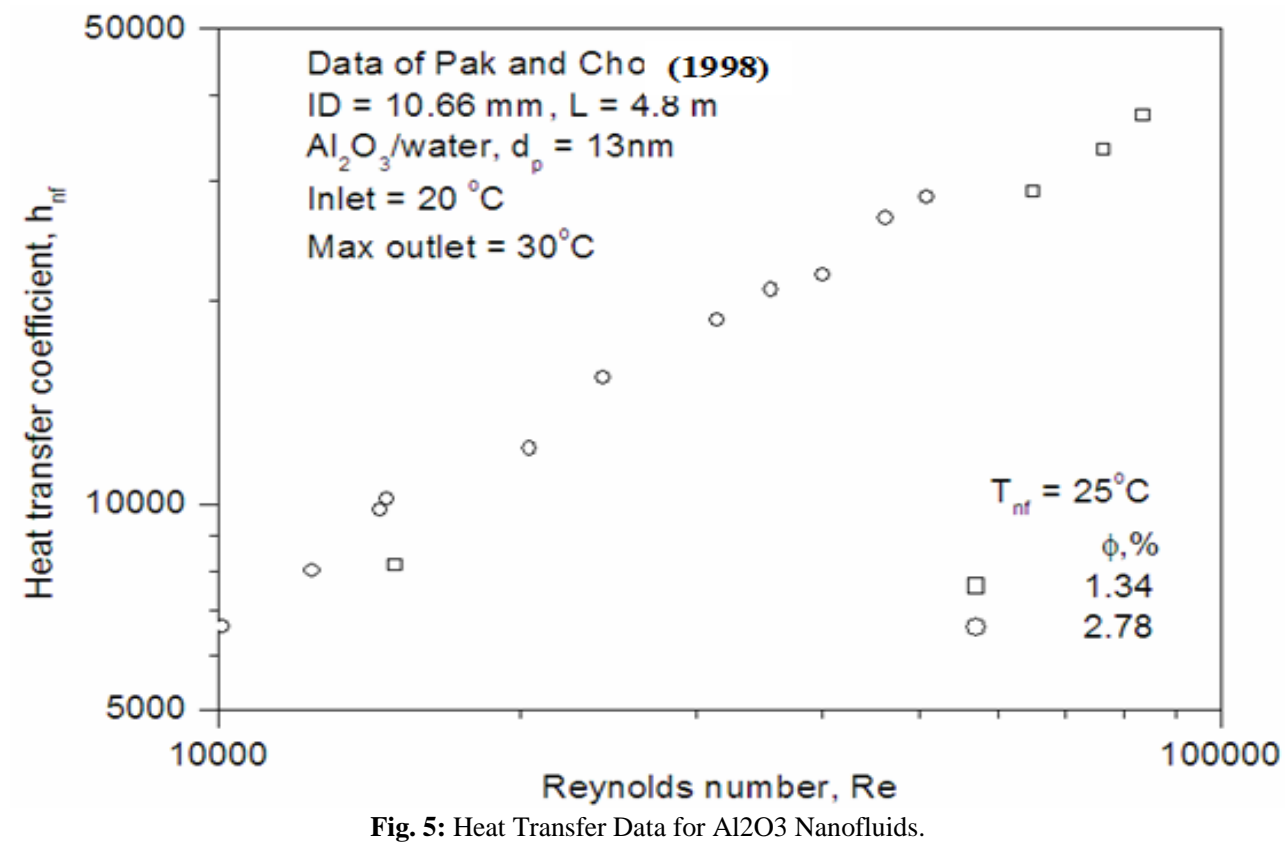

Similar observations were made by Pak and Cho [28]; who conducted experiments with 13-nm-sized Al2O3 nanoparticles dispersed in water. They stated that the heat-transfer coefficient decreased when nanofluid concentration increased to $2.78 \%$, as shown in Figure 5. The authors reported the inlet temperature as $20 \mathrm{oC}$ with a maximum outlet temperature of $30 \mathrm{oC}$. The values of an enhancement ratio lie above the thick line for temperatures lower than $25 \mathrm{oC}$, as shown in Figure 6. Similarly, is also observed to decrease at higher concentrations. The graph for viscosity-thermal conductivity enhancement indicates a higher value of 4.0 if the operating temperature is less than 32 oC. Further experimental data are required to confirm this observation. 


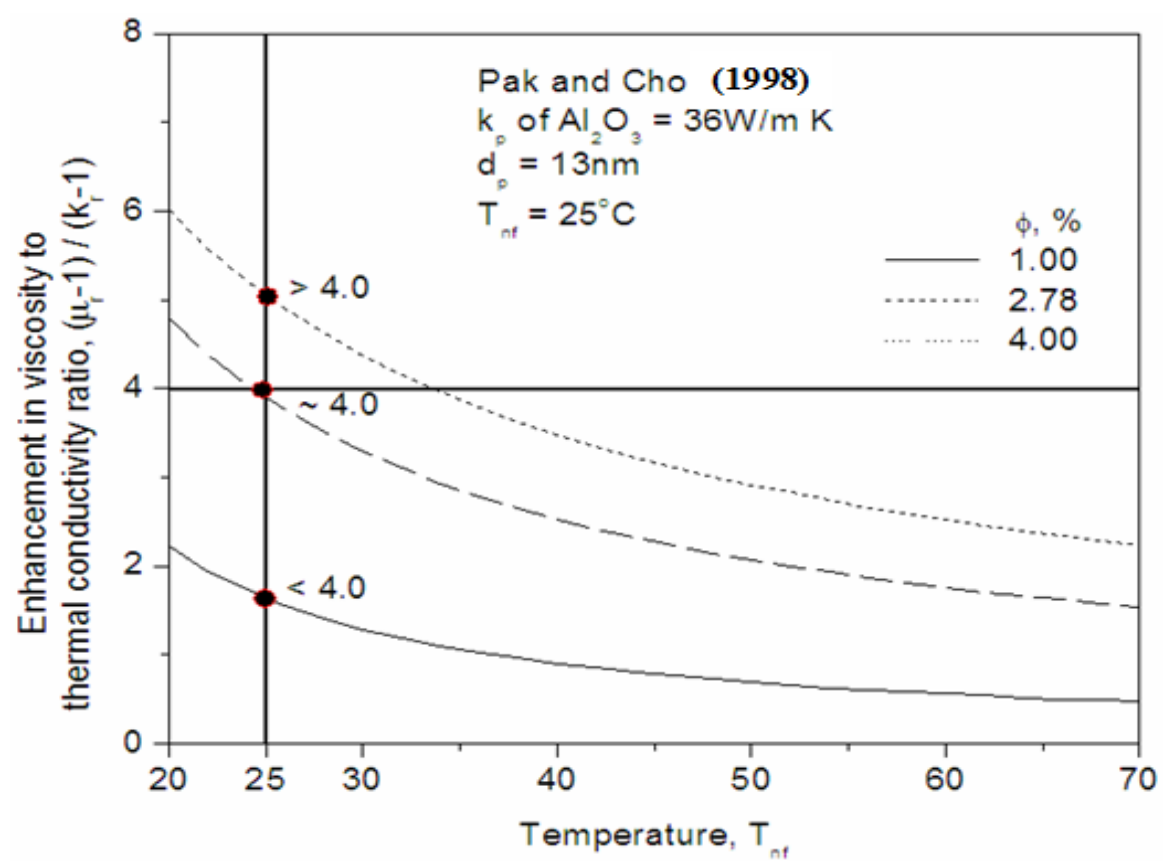

Fig. 6: Variation of Property Enhancement Ratio with Temperature for Al2O3.

\section{Conclusion}

The thermal conductivity of nanofluids depends on various parameters, such as concentration, temperature, particle size, $\mathrm{pH}$, shape, material, and possibly on the manufacturing process of the nanoparticles. Data on the viscosity of nanofluids, available in the literature, are very limited. Theoretical models for the determination of the thermal conductivity and viscosity of nanofluids have been pursued. Experiments with nanofluids indicate that they higher heat transfer coefficients than the base fluid. No significant increase in a pressure drop is reported with nanofluids, compared with values with the base fluid. However, the stability of nanofluids with regard to settlement/agglomeration, especially at higher concentrations, is still a problem for practical applications.

\section{References}

[1] Avsec, J. (2008). The combined analysis of phonon and electron heat transfer mechanism on thermal conductivity for nanofluids. International Journal of Heat and Mass Transfer, 51(19-20), 4589-4598. http://dx.doi.org/10.1016/j.ijheatmasstransfer.2008.02.030.

[2] Batchelor, G. K. (1977). Effect of Brownian-motion on bulk stress in a suspension of spherical-particles. Journal of Fluid Mechanics, 83(1), 97-117. http://dx.doi.org/10.1017/S0022112077001062.

[3] Beck, M., Yuan, Y., Warrier, P., \& Teja, A. (2009). The effect of particle size on the thermal conductivity of alumina nanofluids. Journal of Nanoparticle Research, 11(5), 1129-1136. http://dx.doi.org/10.1007/s11051-008-9500-2.

[4] Brinkman, H. C. (1952). The viscosity of concentrated suspensions and solutions. Journal of Chemical Physics, 20(4), 571-581. http://dx.doi.org/10.1063/1.1700493.

[5] Chon, C. H., \& Kihm, K. D. (2005). Thermal conductivity enhancement of nanofluids by brownian motion. Journal of Heat Transfer, 127(8), 810. http://dx.doi.org/10.1115/1.2033316.

[6] Chon, C. H., Kihm, K. D., Lee, S. P., \& Choi, S. U. S. (2005). Empirical correlation finding the role of temperature and particle size for nanofluid (A12O3) thermal conductivity enhancement. Applied Physics Letters, 87(15), 1531071-1531073. http://dx.doi.org/10.1063/1.2093936.

[7] Das, S. K., Putra, N., Thiesen, P., \& Roetzel, W. (2003). Temperature dependence of thermal conductivity enhancement for nanofluids. Journal of Heat Transfer, 125(4), 567-574. http://dx.doi.org/10.1115/1.1571080.

[8] Duangthongsuk, W., \& Wongwises, S. (2009). Measurement of temperature-dependent thermal conductivity and viscosity of TiO2 - water nanofluids. Experimental Thermal and Fluid Science, 33(4), 706-714. http://dx.doi.org/10.1016/j.expthermflusci.2009.01.005.

[9] Duangthongsuk, W., \& Wongwises, S. (2010). An experimental study on the heat transfer performance and pressure drop of TiO2-water nanofluids flowing under a turbulent flow regime. International Journal of Heat and Mass Transfer, 53(1-3), 334-344. http://dx.doi.org/10.1016/j.ijheatmasstransfer.2009.09.024.

[10] Eastman, J. A., Choi, S. U. S., Li, S., Thompson, L. J., \& Lee, S. (1997). Enhanced thermal conductivity through the development of nanofluids. Proc. Symposium Nanophase and Nanocomposite Materials II, Boston, MA, Materials Research Society.

[11] Hamilton, R. L., \& Crosser, O. K. (1962). Thermal Conductivity of Heterogeneous Two Component Systems. I \& EC Fundamentals, 1, 187191. http://dx.doi.org/10.1021/i160003a005.

[12] He, Y., Jin, Y., Chen, H., Ding, Y., Cang, D., \& Lu, H. (2007). Heat transfer and flow behaviour of aqueous suspensions of TiO2 nanoparticles (nanofluids) flowing upward through a vertical pipe. International Journal of Heat and Mass Transfer, 50(11-12), $2272-2281$. http://dx.doi.org/10.1016/j.ijheatmasstransfer.2006.10.024.

[13] Heris, S. Z., Etemad, S. G., \& Nasr Esfahany, M. (2006). Experimental investigation of oxide nanofluids laminar flow convective heat transfer. International Communications in Heat and Mass Transfer, 33(4), 529-535. http://dx.doi.org/10.1016/j.icheatmasstransfer.2006.01.005.

[14] Hong, J., Kim, S. H., \& Kim, D. (2007). Effect of laser irradiation on thermal conductivity of ZnO. Journal of Physics, 59, 301-304. http://dx.doi.org/10.1088/1742-6596/59/1/063. 
[15] Hwang, K. S., Jang, S. P., \& Choi, S. U. S. (2009). Flow and convective heat transfer characteristics of water-based Al2O3 nanofluids in fully developed laminar flow regime. International Journal of Heat and Mass Transfer, 52(1-2), 193-199. http://dx.doi.org/10.1016/j.ijheatmasstransfer.2008.06.032.

[16] Jang, S. P., \& Choi, S. U. S. (2007). Effects of Various parameters on nanofluid thermal conductivity. Journal of Heat Transfer, 129(5), 617623. http://dx.doi.org/10.1115/1.2712475.

[17] Koo, J., \& Kleinstreuer, C. (2005). Impact analysis of nanoparticle motion mechanisms on the thermal conductivity of nanofluids. International Communications in Heat and Mass Transfer, 32(9), 1111-1118. http://dx.doi.org/10.1016/j.icheatmasstransfer.2005.05.014.

[18] Lee, J. H., Hwang, K. S., Jang, S. P., Lee, B. H., Kim, J. H., Choi, S. U. S., \& Choi, C. J. (2008). Effective viscosities and thermal conductivities of aqueous nanofluids containing low volume concentrations of A12O3 nanoparticles. International Journal of Heat and Mass Transfer, 51(11-12), 2651-2656. http://dx.doi.org/10.1016/j.ijheatmasstransfer.2007.10.026.

[19] Lee, S., Choi, S. U. S., Li, S., \& Eastman, J. A. (1999). Measuring thermal conductivity of fluids containing oxide nanoparticles. Journal of Heat Transfer, 121(2), 280-289. http://dx.doi.org/10.1115/1.2825978.

[20] Lee, S. W., Park, S. D., Kang, S., Bang, I. C., \& Kim, J. H. (2011). Investigation of viscosity and thermal conductivity of SiC nanofluids for heat transfer applications. International Journal of Heat and Mass Transfer, 54(1-3), 433-438. http://dx.doi.org/10.1016/j.ijheatmasstransfer.2010.09.026.

[21] Maïga, S. E. B., Nguyen, C. T., Galanis, N., Roy, G., Maré, T., \& Coqueux, M. (2006). Heat transfer enhancement in turbulent tube flow using Al2O3 nanoparticle suspension. International Journal of Numerical Methods for Heat and Fluid Flow, 16(3): 275-292. http://dx.doi.org/10.1108/09615530610649717.

[22] Masuda, H., Ebata, A., Teramae, K., \& Hishinuma, N. (1993). Alteration of thermal conductivity and viscosity of liquid by dispersing ultra fine particles. Netsu Bussei, 4(4), 227-233. http://dx.doi.org/10.2963/jjtp.7.227.

[23] Prasher, R., Bhattacharya, P., \& Phelan, P. E. (2006). Brownian motion based convective conductive model for the effective thermal conductivity of nanofluids. Journal of Heat Transfer, 128(6), 588-595. http://dx.doi.org/10.1115/1.2188509.

[24] Mintsa, H. A., Roy, G., Nguyen, C. T., \& Doucet, D. (2009). New temperature dependent thermal conductivity data for water-based nanofluids. International Journal of Thermal Sciences, 48(2), 363-371. http://dx.doi.org/10.1016/j.ijthermalsci.2008.03.009.

[25] Murshed, S. M. S., Leong, K. C., \& Yang, C. (2005). Enhanced thermal conductivity of TiO2 - water based nanofluids. International Journal of Thermal Sciences, 44(4), 367-373. http://dx.doi.org/10.1016/j.ijthermalsci.2004.12.005.

[26] Nguyen, C. T., Desgranges, F., Galanis, N., Roy, G., Maré, T., Boucher, S., \& Angue Mintsa, H. (2008). Viscosity data for Al2O3-water nanofluid--hysteresis: is heat transfer enhancement using nanofluids reliable? International Journal of Thermal Sciences, 47(2), 103-111. http://dx.doi.org/10.1016/j.ijthermalsci.2007.01.033.

[27] Nguyen, C. T., Desgranges, F., Roy, G., Galanis, N., Maré, T., Boucher, S., \& Angue Mintsa, H. (2007). Temperature and particle-size dependent viscosity data for water-based nanofluids- Hysteresis phenomenon. International Journal of Heat and Fluid Flow, 28(6), 14921506. http://dx.doi.org/10.1016/j.ijheatfluidflow.2007.02.004.

[28] Pak, B. C., \& Cho, Y. I. (1998). Hydrodynamic and heat transfer study of dispersed fluids with submicron metallic oxide particles Experimental Heat Transfer, 11(2), 151-170. http://dx.doi.org/10.1080/08916159808946559.

[29] Rao, G. S., Sharma, K. V., Chary, S. P., Bakar, R. A., Rahman, M. M., Kadirgama, K., \& Noor, M. M. (2011). Experimental Study on heat transfer coefficient and friction factor of Al2O3 nanofluid in a packed bed column. Journal of Mechanical Engineering and Sciences, 1: 1-15. http://dx.doi.org/10.15282/jmes.1.2011.1.0001

[30] Maxwell, J. C. (1904). A treatise on electricity and magnetism. Cambridge, U.K.: Oxford University Press. 